\title{
Phenotypic and genotypic correlation as expressed in Helicobacter pylori resistance to clarithromycin and fluoroquinolones
}

Dana Binyamin ${ }^{1,2+}$, Nina Pastukh ${ }^{1 \dagger}$, Avi On ${ }^{2,3}$, Maya Paritsky ${ }^{2,4}$ and Avi Peretz ${ }^{1,2,5^{*}}$

\begin{abstract}
Background: Helicobacter pylori susceptibility to clarithromycin and fluoroquinolone can be determined through Etest or molecular assays. We examined the correlation between phenotypic susceptibility (MIC results) and genotypic susceptibility in H. pylori strains isolated from gastric biopsies.

Results: Out of 85 duplicate biopsies obtained from patients from northern Israel who underwent endoscopy, 70 were positive for $\mathrm{H}$. pylori using the CUTest (urease test). These biopsies were cultured for $\mathrm{H}$. pylori and Etest breakpoints were determined for levofloxacin and clarithromycin. H. pylori detection, characterization of wild type (WT) or mutant alleles, and antibiotic resistance were determined molecularly using GenoType HelicoDR kit. Phenotypic and genotype results were compared. The molecular method had higher sensitivity for detection of H. pylori than culture (94.3\% vs. $77.1 \%)$. Resistance to clarithromycin was higher than to levofloxacin by both methods. Levofloxacin resistance was found in 21.2 and $0 \%$ using genotypic and phenotypic methods, respectively. Clarithromycin resistance was found in 66.7 and $62.9 \%$ by genotypic and phenotypic methods, respectively. Some samples were found susceptible by Etest and resistant by GenoType HelicoDR (13/53 samples) and some vice versa (10/53 samples).
\end{abstract}

Conclusion: GenoType HelicoDR kit has high sensitivity rate for $\mathrm{H}$. pylori detection. It has the ability to detect many mutations and can help to determine initial antibiotic treatment at the beginning of therapy. However, there were a few cases where there was a phenotype-genotype mismatch result that could derive from possible causes. For example, a resistance mechanism that is not tested in the kit.

Keywords: Helicobacter pylori, GenoType HelicoDR kits, Clarithromycin, Levofloxacin

\section{Background}

Helicobacter pylori is a gram-negative bacterium known as a common pathogen associated with atrophic and metaplastic changes in the stomach, and peptic ulcer disease [1-3]. Antibiotic treatment for H. pylori commonly includes a combination of proton pump inhibitors (PPIs) and one or several antibacterial agents such as amoxicillin, clarithromycin, and metronidazole [4]. Antibiotic resistance in $H$. pylori has been increasing worldwide, leading to failure of H. pylori eradication [5].

*Correspondence: aperetz@poria.health.gov.il

†Dana Binyamin and Nina Pastukh contributed equally to this work

${ }^{5}$ Hanna Senesh 818/2, Tiberias, Israel

Full list of author information is available at the end of the article
Clarithromycin remains the most powerful antibiotic currently available against $H$. pylori with minimal inhibitor concentrations (MICs) being the lowest compared to the other molecules. Clarithromycin inhibits protein synthesis by binding to the $50 \mathrm{~S}$ bacterial ribosomal subunit [6]. Common resistance mechanisms to clarithromycin include point mutations in bacterial domain $\mathrm{V}$ of $23 S$ rRNA, which prevents antibiotic binding [7]. There are 3 point mutations in the $23 S$ rRNA gene: A2143G, A2142G, and A2142C; these account for $90 \%$ of cases for primary resistance in Western countries [8].

Fluoroquinolone agents (mainly levofloxacin, which is a broad-spectrum quinolone) are an alternative therapy for infections caused by $H$. pylori and serve as second-line treatment [9]. In recent years, resistance 
to fluoroquinolone has increased but seems to have remained low [10]. Fluoroquinolone targets the DNA gyrase, an enzyme responsible for negative supercoiling during the DNA replication process. This enzyme contains two $A$ subunits and two $B$ subunits, encoded by $g y r \mathrm{~A}$ and $g y r \mathrm{~B}$, respectively [11]. Resistance to fluoroquinolones is mainly mediated by a mutation in the Quinolone Resistance Determining Region (QRDR) in the gyrA gene [12].

Antibiotic resistance is usually identified by phenotypic methods that determine the MIC breakpoints, and thus might be efficient for treating infection [13].

Resistance to clarithromycin and fluoroquinolones, which is mostly acquired through point mutations, can be detected by molecular techniques. GenoType HelicoDR (Hain Life Science, Germany) test is a molecular diagnostic method for easy and simultaneous detection of frequent point mutations responsible for clarithromycin and fluoroquinolones resistance [14].

The aim of this study was to evaluate the correlation between in vitro phenotypic susceptibility versus genotypic susceptibility to clarithromycin and fluoroquinolone, as expressed in $H$. pylori strains from gastric biopsies of patients in northern Israel.

\section{Results}

\section{Helicobacter pylori presence in gastric specimens}

A total of 70 positive specimens detected by urease test were examined for H. pylori presence by PCR and culture methods (Table 1). Thirty-four samples were from children (mean age $10.8 \pm 4$ ) and thirty-six from adults (mean age $36 \pm 13.1$ ); 45 females and 25 males.

Sixty-six specimens were positive for $H$. pylori by PCR (94.3\%), 54 (77.1\%) were positive by culture or both. Thirteen samples were found positive only by PCR versus one positive sample determined only by culture method Out of 15 biopsies that were negative for $H$. pylori by urease test, 2 were positive by PCR.

\section{Determination of $H$. pylori resistance to levofloxacin and clarithromycin by PCR or culture}

Sixty-six specimens were examined for levofloxacin and clarithromycin resistance using the GenoType HelicoDR kit and 54 specimens (grown by culture) by E test (Table 2). Both methods detected a higher resistance rate to clarithromycin than to levofloxacin. Similarity in resistance rates to clarithromycin were demonstrated by GenoType HelicoDR kit and Etest (66.7 and 62.9\%, respectively). Resistance to levofloxacin was found only by means of GenoType HelicoDR kit in $21.2 \%$ of specimens.

Only 30.3 and $37.1 \%$ of samples were susceptible to both levofloxacin and clarithromycin by GenoType HelicoDR kit and Etest, respectively).

\section{Determination of MIC breakpoints (phenotype)} in comparison to gene expression (genotype)

Fifty-three samples that were positive for $H$. pylori by both methods were tested by GenoType HelicoDR for distribution of WT and mutant alleles of the gyrA and $23 s$ genes that are known to be associated with fluoroquinolone and

Table 1 H. pylori presence in gastric specimens by PCR and culture methods

\begin{tabular}{|c|c|c|c|c|c|c|}
\hline & \multicolumn{3}{|c|}{ CUTest positive } & \multicolumn{3}{|c|}{ CUTest negative } \\
\hline & Total & Children & Adults & Total & Children & Adults \\
\hline No. of samples & 70 & 34 & 36 & 15 & 8 & 7 \\
\hline Age (mean $\pm S D$ ) & $23.76 \pm 15.8$ & $10.8 \pm 4$ & $36 \pm 13.1$ & $21.96 \pm 11$ & $10.98 \pm 4$ & $34.5 \pm 14$ \\
\hline Male/female & $25 / 45$ & $3 / 15$ & $22 / 30$ & $8 / 7$ & $3 / 4$ & $4 / 4$ \\
\hline $\mathrm{PCR}^{+}$culture $^{+}$ & 53 & 28 & 25 & 0 & 0 & 0 \\
\hline $\mathrm{PCR}^{+}$culture $^{-}$ & 13 & 5 & 8 & 2 & 1 & 1 \\
\hline $\mathrm{PCR}^{-}$culture $^{+}$ & 1 & 1 & 0 & 0 & 0 & 0 \\
\hline $\mathrm{PCR}^{-}$culture $^{-}$ & 3 & 0 & 3 & 13 & 1 & 1 \\
\hline
\end{tabular}

Table 2 Rates of resistance and susceptibility to levofloxacin and clarithromycin in accordance with detection methods (GenoType HelicoDR kit or Etest)

\begin{tabular}{|c|c|c|c|}
\hline Method/antibiotic & Levofloxacin and clarithromycin susceptibility & Levofloxacin resistance & Clarithromycin resistance \\
\hline GenoType HelicoDR ( $n_{\text {positive }}=66$ ) & $20(30.3 \%)$ & $14(21.2 \%)^{\mathrm{a}}$ & $44(66.7 \%)^{a}$ \\
\hline E test $\left(n_{\text {positive }}=54\right)$ & $20(37.1 \%)$ & $0(0 \%)$ & $34(62.9 \%)$ \\
\hline
\end{tabular}

a Resistant to both antibiotics 
clarithromycin resistance, respectively. Strains with mutations in gyrA (N87K, D91N, D91G, and D91Y) were determined as resistant to levofloxacin; strains with mutations in $23 S$ rRNA (A2142G, A2142C, and A2143G) were determined as resistant to clarithromycin. For each sample the MIC was determined by Etest, and resistance to clarithromycin was determined by MIC higher than $0.5 \mu \mathrm{g} / \mathrm{mL}$ and to levofloxacin by MIC higher than $1 \mu \mathrm{g} / \mathrm{mL}$ (Table 3 ).

The gyrA WT genes were mainly identified in 40 samples (23 in children and 17 in adults) and all were in levofloxacin-susceptible MIC zones $(0.38-0.75 \mu \mathrm{g} / \mathrm{mL})$, in agreement with the presence of the WT detected genes. Mutants to gyrA were found in 14 samples, with more than one mutation in several. A mutation in D91Y was found in only 2 adult patients.

All of the strains with mutant alleles had an MIC $\leq 1$, and thus were susceptible by the phenotypic method, but resistant in the genotypic method (Fig. 1).

The most frequent allele detected in the $23 \mathrm{~s}$ rRNA gene was the A2143G mutation (in $69.8 \%$ of samples, 19 in children and 18 in adults), with most of these (62.2\%)

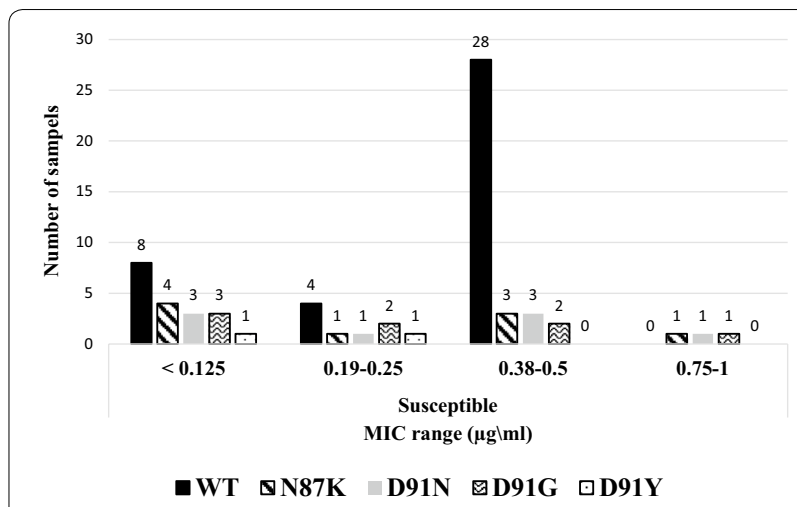

Fig. 1 Samples distribution by MIC ranges and alleles appearance for fluoroquinolone antibiotic

demonstrating an MIC to clarithromycin $>1$ (resistant by the phenotypic method as well). Of the 15 specimens with WT alleles, $66.7 \%$ were found to be resistant by the Etest method (Table 3; Fig. 2). The A2142G mutation was not found in the study group.

Table 3 Distribution of genes (gyrA, 23S) in accordance with MIC breakpoints for fluoroquinolone and clarithromycin antibiotics

\begin{tabular}{|c|c|c|c|c|c|c|c|c|}
\hline \multirow[t]{2}{*}{ Gene } & \multirow[t]{2}{*}{ No. of samples } & \multicolumn{7}{|c|}{ MIC range $(\mu \mathrm{g} / \mathrm{mL})$} \\
\hline & & $<0.125$ & $0.19-0.25$ & $0.38-0.5$ & $0.75-1$ & $1.5-2$ & 3 & $>4$ \\
\hline \multicolumn{9}{|c|}{ gyrA87 and gyrA91 genes } \\
\hline \multicolumn{9}{|c|}{ Children } \\
\hline WT & 23 & 3 & 2 & 18 & & & & \\
\hline N87K & 5 & 1 & 1 & 2 & 1 & & & \\
\hline D91N & 4 & 1 & 1 & 1 & 1 & & & \\
\hline D91G & 4 & 1 & 1 & 1 & 1 & & & \\
\hline D91Y & 0 & & & & & & & \\
\hline \multicolumn{9}{|l|}{ Adults } \\
\hline WT & 17 & 5 & 2 & 10 & & & & \\
\hline N87K & 4 & 3 & & 1 & & & & \\
\hline D91N & 4 & 2 & & 2 & & & & \\
\hline D91G & 4 & 2 & 1 & 1 & & & & \\
\hline D91Y & 2 & 1 & 1 & & & & & \\
\hline \multicolumn{9}{|c|}{$23 S$ rRNA (rrl) genes } \\
\hline \multicolumn{9}{|c|}{ Children } \\
\hline WT & 9 & & 2 & 2 & 2 & 1 & 2 & \\
\hline A2142G & 0 & & & & & & & \\
\hline A2142C & 2 & & & 1 & 1 & & & \\
\hline A2143G & 19 & 2 & 1 & 5 & 1 & 5 & 4 & 1 \\
\hline \multicolumn{9}{|l|}{ Adults } \\
\hline WT & 7 & 1 & & 1 & & 1 & 2 & 2 \\
\hline A2142G & 0 & & & & & & & \\
\hline A2142C & 2 & & & & & & 1 & 1 \\
\hline A2143G & 18 & 2 & & 3 & & 6 & 3 & 4 \\
\hline
\end{tabular}


Correlation between susceptibility determination methods-GenoType HelicoDR and Etest

Comparison between the results of susceptibility tests obtained by GenoType HelicoDR and Etest was done on 53 positive samples (Table 4). In regard to levofloxacin, 40 gastric samples were found to be susceptible by GenoType HelicoDR kit and Etest. However, 13 samples demonstrated resistance by GenoType HelicoDR but were susceptible by Etest. These findings indicate a possible intermediate correlation between two methods for levofloxacin resistance determination.

In regard to clarithromycin, 24 samples were found to be resistant by Etest and GenoType HelicoDR. Six samples were susceptible by both methods. A few samples exhibited mismatched results for the two methods; some were found susceptible by Etest and resistant by GenoType HelicoDR (13 samples) and some were found susceptible by GenoType HelicoDR and resistant by Etest (10 samples). Consequently, intermediate correlation between both methods was found.

The relative risk for clarithromycin resistance was higher than 1 (1.07 and 1.04 for MUT genotype in correlation to resistance in Etest and WT genotype in correlation to susceptibility in Etest, respectively). This means that the molecular method could serve as an alternative for the Etest for prediction of susceptibility of strains to Clarithromycin.
Table 4 A correlation of antibiotic susceptibility in accordance with GenoType HelicoDR kit and Etest

\begin{tabular}{|c|c|c|c|c|}
\hline \multirow{3}{*}{$\begin{array}{l}\text { Antibiotic } \\
\text { Method }\end{array}$} & \multirow{2}{*}{\multicolumn{2}{|c|}{$\begin{array}{l}\text { Levofloxacin } \\
\text { Etest }\end{array}$}} & \multirow{2}{*}{\multicolumn{2}{|c|}{$\begin{array}{l}\text { Clarithromycin } \\
\text { Etest }\end{array}$}} \\
\hline & & & & \\
\hline & Resistance & Susceptible & Resistance & Susceptible \\
\hline \multicolumn{5}{|c|}{ GenoType HelicoDR kit } \\
\hline Resistance & 0 & $\begin{array}{l}13 / 53 \\
(24.53 \%)\end{array}$ & $\begin{array}{l}24 / 53 \\
(45.28 \%)\end{array}$ & $\begin{array}{l}13 / 53 \\
(24.53 \%)\end{array}$ \\
\hline Susceptible & 0 & $\begin{array}{l}40 / 53 \\
(75.47 \%)\end{array}$ & $\begin{array}{l}10 / 53 \\
(18.87 \%)\end{array}$ & 6/53 (11.32\%) \\
\hline
\end{tabular}

\section{Discussion}

In the current study a higher $H$. pylori prevalence was found among women, but no significant difference was found between children and adults.

Helicobacter pylori presence in gastric specimens can be assessed by various methods including molecular PCR assay (GenoType HelicoDR kit) and culture. Our findings demonstrate that PCR is a more sensitive method $(80.3 \%$ sensitivity, $75.0 \%$ specificity), with a higher $H$. pylori detection rate compared to culture [14-17].

The study group consisted of patients who underwent a rapid urease test and received a positive result. It is important to mention that the urease test is characterized

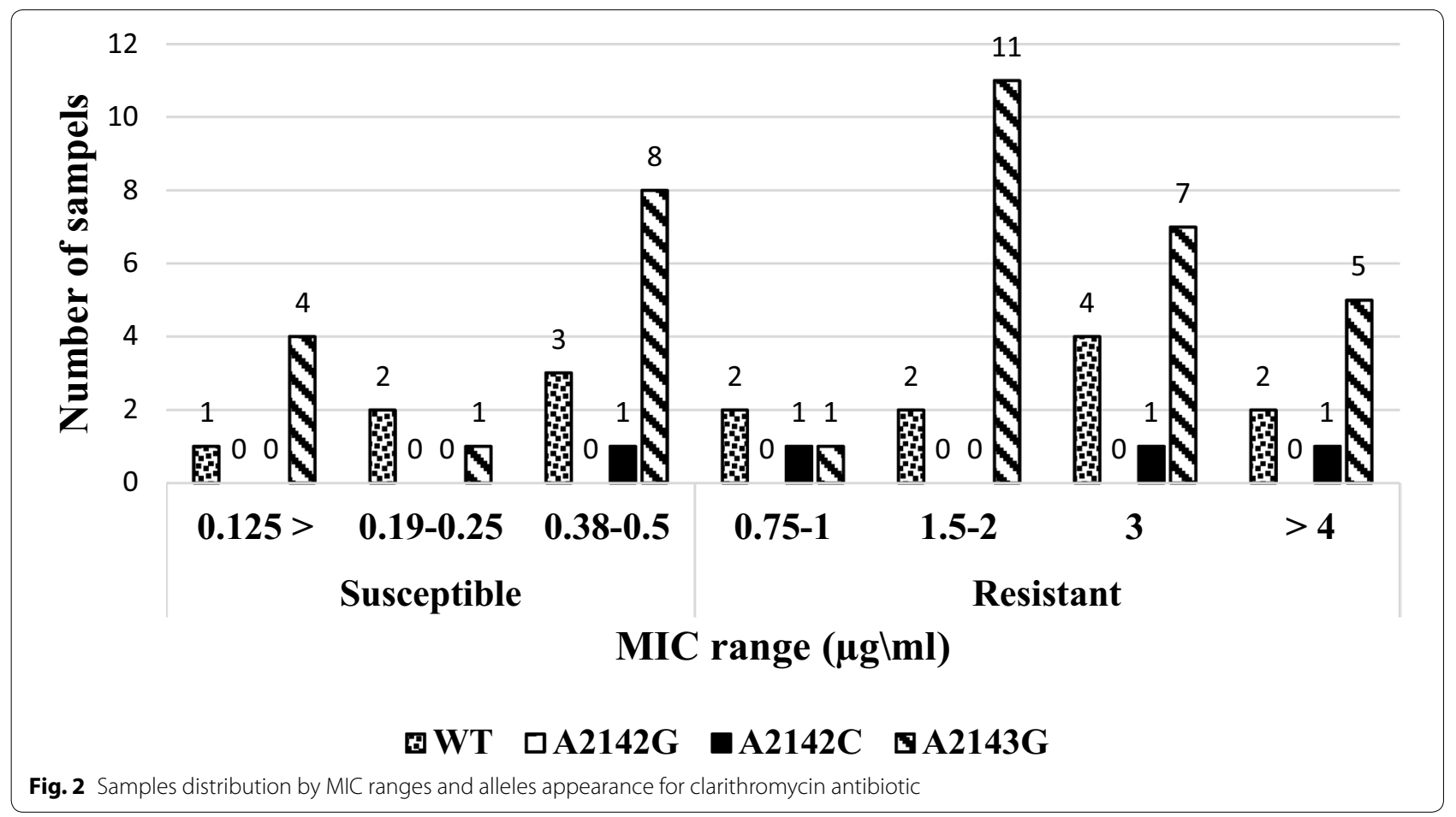


by a poor sensitivity, and indeed 2 out of 15 CUTest negative specimens were positive by PCR and 3 out of 70 CUTest positive specimens were found negative by PCR and culture. Thus, it could be concluded that rapid urease test is a non-accurate assay with a probability of a false positive and negative results; therefore methods such as PCR and culture are recommended for $\mathrm{H}$. pylori detection. Furthermore, performance of culture or PCR enables determination of antibiotic susceptibility profile for adjustment of effective antibiotic treatment and purposes of epidemiological research.

A phenotype-genotype correlation for levofloxacin and clarithromycin resistance profiles has been examined. MIC measurements by Etest demonstrated results expressed as a phenotype. Determination of antibiotic resistance profile by bacterial culture and Etest technique is common after a treatment failure. Although this procedure could prevent antibiotic failure, this process is not routinely carried out in all labs due to the difficulty to culture the bacterium and the excessive time required. As a result, many alternative methods for antibiotic resistance detection are available, such as GenoType HelicoDR kit.

This kit was designed through validation on strains with known MIC values for clarithromycin and fluoroquinolones and known genotypes encoded by $23 S$ rRNA and $g y r \mathrm{~A}$ [14]. The kit enables detection of strains' profile genotypes, expressed as mutant or WT alleles.

In the current study resistance to fluoroquinolones was detected only by the molecular method GenoType HelicoDR kit, with a higher resistance rate compared to data published in Israel in $2015[15,16]$. This finding could be explained by the high sensitivity of the molecular kit, which is not routinely used, enabling detection of genotypic resistance, in accordance with a worldwide trend of a rise in fluoroquinolones resistance $[14,17,18]$.

In addition, resistance rate to clarithromycin has increased, and is 3 times higher (similar rates in both methods) in comparison to data published earlier in Israel, in accordance with the global increasing trend [19]. A possible explanation for a lower resistance rate to fluoroquinolones in comparison to clarithromycin could be due to its later addition to treatment protocols of $H$. pylori infection.

The increase in resistance rate emphasizes the need for accurate detection of antibiotic resistance for an optimal adjustment of personal treatment therapy. Furthermore, success of eradication treatment is enabled by a prior, early determination of antibiotic resistance [17].

The MIC values for fluoroquinolones were low; this may indicate the presence of mainly the susceptible phenotype profile, in accordance with samples that contained WT alleles indicating a susceptible genotype profile.
Therefore, a concordance between phenotype and genotype expression was observed at the susceptibility area. However, in some specimens a difference between phenotype and genotype expression was observed, expressed as susceptible MIC values and mutant alleles, in accordance with other published research [20]. Previous studies had shown that a profile of levofloxacin genotype resistance detected by GenoType HelicoDR kit is consistent with therapeutic outcomes. In contrast, a high correlation between phenotype and genotype resistance profiles to levofloxacin was shown in other studies [21].

For clarithromycin, concordance between genotype analysis and phenotype results was observed in more than $60 \%$ of the specimens. However, some differences between phenotype and genotype profiles were observed; these were characterized by phenotypic susceptibility and genotypic resistance or vice versa, in contrast to other studies [22-24].

Clarithromycin resistance has been associated with a higher risk of treatment failure. A2143G mutation has a higher risk of eradication failure [15, 16, 21, 25]. This mutation demonstrated the highest rate among examined mutations, in accordance with other studies [14, 22, 24].

Although many samples demonstrated a phenotypegenotype correlation, no statistically significant relation was found. This could be an outcome of a small sample size group or bias due to demographic data such as age, gender, ethnicity, or a case of $H$. pylori recurrence.

In cases of specimens demonstrating a genotypic mutant a susceptible phenotypic profile, a possible explanation could be the presence of a mixed bacterial population residing in the gastric specimens that may consist of susceptible and resistant strains [26]. In fact, this correlates with appearance of w.t. and mutant gene in the same sample. The significant advantage of the molecular method is a direct examination of gastric specimens with a complete diversity of strains (susceptible, resistant, or both) in contrast to the culture method, which is based on a random selection of colonies to perform the Etest. Another explanation for the difference in phenotype-genotype result could be that strains of $H$. pylori harbor two copies of the $23 S$ rRNA gene in the chromosomal DNA; a mutation in one gene copy is shown to enable resistance to clarithromycin [27]. Therefore, GenoType HelicoDR method detects strains with a genotypic resistance profile that may not be detected by a phenotype assay [25, 28].

In cases of phenotypic resistance expression accompanied by genotypic susceptibility, a reasonable explanation could be the presence of additional resistance mechanisms that were not examined in this study. For instance, a well-known mechanism for clarithromycin resistance is the efflux pump system or other point mutations such as T2182C and C2611A that have been associated with low 
resistance levels [29]. Even so, the examined alleles are present in higher rates than other resistance mechanisms [8].

Another limitation of the kit is lack of necessary susceptibility detection of amoxicillin and metronidazole, two antibiotic agents used against $H$. pylori. In addition, in GenoType HelicoDR test, as in other molecular assays, a possible risk of contamination of the amplified DNA during PCR performance is present, which may yield false positive outcomes.

\section{Conclusions}

GenoType HelicoDR kit has a high sensitivity rate for H. pylori detection in accordance with others studies [14-17]. This molecular assay can detect a mixture of genotypes and could successfully analyze biopsies without transport or storage limitations at sort time. Consequently, it might serve as an effective option for rapid $H$. pylori determination and for initial antibiotic selection at the beginning of therapy Due to the intermediate correlation between phenotype-genotype results, culture performance and susceptibility tests should be done for specific antibiotic treatment adjustment.

\section{Experimental procedures}

\section{Patient selection}

The specimens used for this study were gastric biopsy samples from patients residing in northern Israel who had undergone endoscopy due to abdominal pain or discomfort, from March 2015 to April 2016.

Eighty-five patients underwent gastroscopy procedures; 42 were children (mean age 10.8 years) and 43 were adults (mean age 35.7 years). In case of suspected H. pylori infection a rapid urease test (CUTest; Temmler Pharma $\mathrm{GmbH} \& \mathrm{Co}$ ) was performed on the antrum biopsies.

A total of 70 patients were determined as positive by rapid urease test and 15 were found negative; subsequently all 85 biopsies were referred to a microbiology lab.

None of the patients included in the study received antibiotic treatment during the month preceding the gastroscopy procedure. The study was approved by the institutional review board and informed consent was obtained from all study participants. Each specimen was split into two duplicates for purposes of bacterial culture and molecular assay.

\section{Bacterial culture and determination of in vitro susceptibility}

All biopsy specimens were placed in sterile Eppendorf tubes containing $1 \mathrm{~mL}$ sterile physiological solution $(0.9 \% \mathrm{NaCl})$ and were sent to the Clinical Microbiology
Lab within 30 min after the gastroscopy procedure under cold conditions. First, specimens were minced manually with a sterile scalpel and seeded on Modified BD Helicobacter Agar (BD Diagnostics, Sparks, MD, USA) in accordance with the relevant protocol. Then, the plates were incubated for 7 days at $37{ }^{\circ} \mathrm{C}$ in a micro-aerobic atmosphere $\left(5 \% \mathrm{O}_{2}\right.$ and $\left.10 \% \mathrm{CO}_{2}\right)$ produced by a gas generating system adapted for Campylobacter (Campy$\mathrm{Gen}^{\mathrm{TM}}$, Gamidor Diagnostics). If no bacterial growth was seen after 7 days, an additional 3 days of incubation were added. H. pylori was identified based on a Gram-staining procedure followed by positive oxidase, catalase, and urease tests.

Antibiotic susceptibility tests were performed using the Etest for determination of each antibiotic's MIC (minimum inhibitory concentration) against $H$. pylori.

\section{Determination of MIC}

Samples from primary plates were suspended in $0.85 \%$ $\mathrm{NaCl}$ solution to a $3.0 \mathrm{McF}$ arland standard to be subjected to Etest (bioMérieux, Durham, USA) on Mueller-Hinton agar with $10 \%$ horse blood (hy-lab, Israel) for levofloxacin. The suspensions were incubated for $72 \mathrm{~h}$ at $35{ }^{\circ} \mathrm{C}$ in microaerobic atmospheric condition (Campy$\mathrm{Gen}^{\mathrm{TM}}$, Gamidor Diagnostics, Israel). MIC breakpoints were defined as the lowest concentration of an antimicrobial to inhibit visible growth of a microorganism.

Interpretation of susceptibility tests results was performed in accordance with European Committee on Antimicrobial Susceptibility Testing (EUCAST) recommendations. Based on these recommendations, H. pylori isolates were considered resistant to levofloxacin when MIC level was greater than $1 \mu \mathrm{g} / \mathrm{mL}$ and considered resistant to clarithromycin when MIC level was greater than $0.5 \mu \mathrm{g} / \mathrm{mL}$; intermediate resistance was defined by $\mathrm{MIC}=0.5$ and $\leq 0.25 \mu \mathrm{g} / \mathrm{mL}$ for susceptible strains.

The MIC was read at the point of complete inhibition of all growth, including hazes and isolated colonies. For MIC QC the H. pylori 43504 strain was used.

\section{Helicobacter pylori molecular identification, antibiotic resistance determination by GenoType HelicoDR kit DNA extraction from gastric biopsies}

Tissue obtained from gastroscopic biopsy was minced using a sterile scalpel, lysed by tissue lysis buffer and Proteinase-K enzyme (Bioneer, Daejeon, Korea), and incubated for $10 \mathrm{~min}$ in $60^{\circ} \mathrm{C}$. Then, total DNA was extracted with an AccuPrep Genomic DNA Extraction Kit (Bioneer, Daejeon, Korea). This kit contains a glass filter fixed in a column tube that can bind efficiently to DNA in the presence of chaotropic salts. The spin-column method was used to eliminate contaminants and enzyme inhibitors. Additional washing steps were performed for proteins 
and salt removal, then high-purity DNA was eluted using a Tris-EDTA (pH 8.0) low-concentration elution buffer. DNA samples were stored at $-20^{\circ} \mathrm{C}$ until required. Aliquots of $50 \mu \mathrm{L}$ were used for PCR amplification.

\section{PCR amplification}

DNA regions involved in acquired clarithromycin ( $r r l$ gene) or fluoroquinolone ( $g y r A$ gene) resistance were amplified by multiplex PCR as previously described [1416]. Briefly, reaction mixtures (volume of $45 \mu \mathrm{L}$ ) contained $1 \times 5 \mu \mathrm{L}$ reaction buffer, $2 \mu \mathrm{L} \mathrm{MgCl}_{2}, 3 \mu \mathrm{L}$ DDW, $35 \mu \mathrm{L}$ biotinylated primers and nucleotide mixture, and $0.2 \mu \mathrm{L}$ Hot Star Taq polymerase (hy-labs, Rehovot, Israel); $5 \mu \mathrm{L}$ of DNA were added to each reaction mixture. PCR reactions were carried out for 35 cycles for each biopsy specimen. The denaturation cycle consisted of 1 cycle at $95{ }^{\circ} \mathrm{C}$ for $5 \mathrm{~min}$, followed by 10 cycles at $95^{\circ} \mathrm{C}$ for $30 \mathrm{~s}$, and $58^{\circ} \mathrm{C}$ for $2 \mathrm{~min}$. Then, 25 cycles were composed of a first step at $95{ }^{\circ} \mathrm{C}$ for $25 \mathrm{~s}$, a second step at $53{ }^{\circ} \mathrm{C}$ for $40 \mathrm{~s}$, and a third step at $70{ }^{\circ} \mathrm{C}$ for $40 \mathrm{~s}$. The PCR reaction terminated with $8 \mathrm{~min}$ at $70{ }^{\circ} \mathrm{C}$.

\section{Hybridization}

Hybridization was performed at a temperature of $45^{\circ} \mathrm{C}$. The denaturation solution was mixed with $20 \mu \mathrm{L}$ of the amplified sample and was hybridized using a standard hybridization protocol. The hybridization forms were detected by enzyme immunoassay upon addition of conjugate and substrate solution.

This strip was coated with different specific oligonucleotides (DNA probes) designed to hybridize with the sequences of the amplified wild type (WT probes) or the mutant alleles (MUT probes). GenoType HelicoDR test was designed for identification of mutations in A2142C, A2142G, and A2143G for 23S rRNA gene (encoding for clarithromycin resistance) and in N87K, D91N, D91G, and D91Y for gyrA gene (encoding for fluoroquinolone resistance).

Validation control bands are designed on the strip, such as: a conjugate control (CC), amplification control (AC), and H. pylori (HP), which must appear in addition to gyrA and $23 S$ control bands.

\section{Interpretation}

Strips were attached to the evaluation sheet after hybridization. A determination of positive band was done through comparison of each band's stain intensity with the amplification control band. More intense stain as compared with the amplification band was interpreted as positive for the presence of the specific allele.

In case of outcome different than strains resistant to clarithromycin or fluoroquinolone, or strains resistant to both antibiotics, a wild type (WT) strain was determined by the presence of WT bands. Mutants were determined by presence of MUT band. Each amplified sample could exhibit more than one band for each type of gene (WTs or MUTs).

\section{Statistical analysis}

All measured variables were tabulated by descriptive statistics. Categorical variables were summarized in tables providing sample size, and absolute and relative frequency by Culture and PCR.

Sensitivity and specificity analysis and $95 \%$ confidence intervals (CIs) were computed using a $2 \times 2$ table, in order to evaluate conditional probability and to predict positive or normal condition in concordance with the test result. The data was analyzed using $\operatorname{SAS}^{\circledR}$ version 9.3 (SAS Institute, Cary, North Carolina, USA).

Categorical data were compared using Chi square test. The level of statistical significance was specified as 0.05 . Statistical analyses were performed using SPSS 23 statistical software. Relative risk was calculated for determination of the association strength between MUT genotype determined by molecular assay and phenotype resistance determined by Etest for Clarithromycin.

\section{Abbreviations \\ WT: wild type; MUT: mutation; MIC: minimal inhibitor concentration.}

\section{Authors' contributions}

DB and NP performed the experiments, analysed and interpreted the data. AP conceived and designed the study and participated in the interpretation. AO and MP collected the data. All authors have provided comments on the drafts. All authors read and approved the final manuscript.

\section{Author details}

${ }^{1}$ Clinical Microbiology Laboratory Baruch Padeh Medical Center, Poriya, affiliated with the Faculty of Medicine, Bar Ilan University, Galilee, Israel. ${ }^{2}$ The Faculty of Medicine in the Galilee, Bar Ilan University, Zefat, Israel. ${ }^{3}$ Pediatric Gastrointestinal Unit, Baruch Padeh Medical Center, Poriya affiliated with the Faculty of Medicine, Bar Ilan University, Galilee, Israel. ${ }^{4}$ Gastrointestinal Unit, Baruch Padeh Medical Center, Poriya affiliated with the Faculty of Medicine, Bar Ilan University, Galilee, Israel. ${ }^{5}$ Hanna Senesh 818/2, Tiberias, Israel.

\section{Acknowledgements}

Not applicable.

\section{Competing interests}

The authors declare that they have no competing interests.

\section{Availability of data and materials}

The datasets used and/or analyzed during the current study are available from the corresponding author on reasonable request.

\section{Consent for publication}

Not applicable.

\section{Ethics approval and consent to participate}

The study is approved by the Helsinki Committee of the Medical Center, No. committee approval is 23-13-POR.

\section{Funding}

This research did not receive any specific grant from funding agencies in the public, commercial, or not-for-profit sectors. 


\section{Publisher's Note}

Springer Nature remains neutral with regard to jurisdictional claims in published maps and institutional affiliations.

Received: 29 July 2017 Accepted: 17 August 2017

Published online: 25 August 2017

\section{References}

1. Blaser MJ, Atherton JC. Helicobacter pylori persistence: biology and disease. J Clin Invest. 2004;113:321-33.

2. Forman D, Newell DG, Fullerton F, et al. Association between infection with Helicobacter pylori and risk of gastric cancer: evidence from a prospective investigation. BMJ. 1991;302:1302-5.

3. Miwa H, Sakaki N, Sugano K, et al. Recurrent peptic ulcers in patients following successful Helicobacter pylori eradication: a multicenter study of 4940 patients. Helicobacter. 2004;9:9-16.

4. Malfertheiner P, Megraud F, O'Morain C, et al. Current concepts in the management of Helicobacter pylori infection: the Maastricht III Consensus Report. Gut. 2007:56:772-81

5. Megraud F. H. pylori antibiotic resistance: prevalence, importance, and advances in testing. Gut. 2004:53:1374-84.

6. Whitman MS, Tunkel AR. Azithromycin and clarithromycin overview and comparison with erythromycin. Infect Control Hosp Epidemiol. 1992:13:357-68.

7. Versalovic J, Shortridge D, Kibler K, et al. Treatment of Helicobacter pylori infection: meeting the challenge of antimicrobial resistance. World J Gastroenterol. 2014;20:9898-911.

8. Tanaka SK, Graham DY, Go MF. Mutations in 23S rRNA are associated with clarithromycin resistance in Helicobacter pylori. Antimicrob Agents Chemother. 1996:40(2):477-80.

9. Romano M, Cuomo A, Gravina AG, et al. Empirical levofloxacin-containing versus clarithromycin-containing sequential therapy for Helicobacter pylori eradication: a randomised trial. Gut. 2010;59:1465-70.

10. Ghotaslou R, Leylabadlo HE, AsI YM. Prevalence of antibiotic resistance in Helicobacter pylori: a recent literature review. World J Methodol. 2015;5:164.

11. Ruiz J. Mechanisms of resistance to quinolones: target alterations, decreased accumulation and DNA gyrase protection. J Antimicrob Chemother. 2003;51(5):1109-17.

12. Moore RA, Beckthold B, Wong S, et al. Nucleotide sequence of the gyrA gene and characterization of ciprofloxacin-resistant mutants of Helicobacter pylori. Antimicrob Agents Chemother. 1995;39:107-11.

13. Andrews JM. Determination of minimum inhibitory concentrations. J Antimicrob Chemother. 2001;48(Suppl 1):5-16.

14. Cambau E, Allerheiligen V, Coulon C, et al. Evaluation of a new test, genotype HelicoDR, for molecular detection of antibiotic resistance in Helicobacter pylori. J Clin Microbiol. 2009;47:3600-7.
15. Lee $\mathrm{JH}$, Shin $\mathrm{JH}$, Roe $\mathrm{H}$, et al. Impact of clarithromycin resistance on eradication of Helicobacter pylori in infected adults. Antimicrob Agents Chemother. 2005:49:1600-3.

16. Peretz A, Paritsky M, Dinisman-Zavulunov E, et al. Susceptibility of Helicobacter pylori to levofloxacin and rifampicin in Israel. Microb Drug Resist. 2015;21:448-51.

17. Lee JW, Kim N, Nam RH, et al. GenoType HelicoDR test in the determination of antimicrobial resistance of Helicobacter pylori in Korea. Scand J Gastroenterol. 2014:49:1058-67.

18. Tanih NF, Ndip RN. Molecular detection of antibiotic resistance in South African isolates of Helicobacter pylori. Gastroenterol Res Pract. 2013;2013:259457.

19. Peretz A, Paritsky M, Nasser O, et al. Resistance of Helicobacter pylori to tetracycline, amoxicillin, clarithromycin and metronidazole in Israeli children and adults. J Antibiot. 2014;67:555-7.

20. Deyi VYM, Burette A, Bentatou Z, et al. Practical use of GenoType ${ }^{\circledR}$ HelicoDR, a molecular test for Helicobacter pylori detection and susceptibility testing. Diagn Microbiol Infect Dis. 2011;70:557-60.

21. Liou JM, Chang CY, Sheng WH, et al. Genotypic resistance in Helicobacter pylori strains correlates with susceptibility test and treatment outcomes after levofloxacin- and clarithromycin-based therapies. Antimicrob Agents Chemother. 2011:55:1123-9.

22. Aguilera-Correa JJ, Urruzuno P, Barrio J, et al. Detection of Helicobacter pylori and the genotypes of resistance to clarithromycin and the heterogeneous genotype to this antibiotic in biopsies obtained from symptomatic children. Diagn Microbiol Infect Dis. 2017;87:150-3.

23. De Francesco V, Zullo A, lerardi E, et al. Phenotypic and genotypic Helicobacter pylori clarithromycin resistance and therapeutic outcome: benefits and limits. J Antimicrob Chemother. 2010;65:327-32.

24. Trespalacios AA, Otero W, Caminos JE, et al. Phenotypic and genotypic analysis of clarithromycin-resistant Helicobacter pylori from Bogotá DC, Colombia. J Microbiol. 2013;51:448-52.

25. De Francesco V, Margiotta M, Zullo A, et al. Clarithromycin-resistant genotypes and eradication of Helicobacter pylori. Ann Intern Med. 2006;144:94-100.

26. Noguchi N, Rimbara E, Kato A, et al. Detection of mixed clarithromycinresistant and-susceptible Helicobacter pylori using nested PCR and direct sequencing of DNA extracted from faeces. J Med Microbiol. 2007;56:1174-80

27. Marais A, Monteiro L, Occhialini A, et al. Direct detection of Helicobacter pylori resistance to macrolides by a polymerase chain reaction/DNA enzyme immunoassay in gastric biopsy specimens. Gut. 1999:44:463-7.

28. Oleastro M, Ménard A, Santos A, et al. Real-time PCR assay for rapid and accurate detection of point mutations conferring resistance to clarithromycin in Helicobacter pylori. J Clin Microbiol. 2003;41:397-402.

29. Francesco VD, Zullo A, Hassan C, et al. Mechanisms of Helicobacter pylori antibiotic resistance: an updated appraisal. World J Gastrointest Pathophysiol. 2011;2:35-41.

\section{Submit your next manuscript to BioMed Central and we will help you at every step:}

- We accept pre-submission inquiries

- Our selector tool helps you to find the most relevant journal

- We provide round the clock customer support

- Convenient online submission

- Thorough peer review

- Inclusion in PubMed and all major indexing services

- Maximum visibility for your research

Submit your manuscript at www.biomedcentral com/submit 